\title{
Pyroptosis targeting via mitochondria: an educated guess to fast-track COVID-19 therapies
}

\author{
Michelangelo Campanella ${ }^{1}$, Aarti Singh ${ }^{1}$, and Daniela Strobbe ${ }^{2}$ \\ ${ }^{1}$ Royal Veterinary College, University of London \\ ${ }^{2}$ University of Rome Tor Vergata Department of Biology
}

April 18, 2021

\begin{abstract}
Pyroptosis, is a specialized form of inflammatory cell death which aids the defensive response against invading pathogens. Its tight regulation is lost during infection by the severe acute respiratory coronavirus 2 (SARS-CoV-2) and thus uncontrolled pyroptosis disrupts the immune system and the integrity of organs defining the critical conditions in patients with high viral load. Molecular pathways engaged downstream to the formation and stabilization of the inflammasome -required to execute the process- have been uncovered and drugs are available for their regulation. On the contrary, pharmacological inferring of the upstream events - which are critical to sense and interpret the initial damage by the pathogen- is far from being elucidated. This limits our capacity to identify early markers and targets to ameliorate SARS-CoV-2 linked pyroptosis. Here we aim to raise attention on mitochondria and pathways leading to its dysfunction with the goal to inform early steps of inflammasome and devise tools to interpret and counteract diseases by the SARS-CoV-2.
\end{abstract}

\section{Hosted file}

Main Document.pdf available at https://authorea.com/users/408553/articles/518512-pyroptosistargeting-via-mitochondria-an-educated-guess-to-fast-track-covid-19-therapies

\section{Hosted file}

Figure 1.pdf available at https://authorea.com/users/408553/articles/518512-pyroptosistargeting-via-mitochondria-an-educated-guess-to-fast-track-covid-19-therapies 